\title{
Primary sarcoma of the breast in the young Rwandan females
}

Uyisenga Jeanne $\mathrm{P}^{1,2}$, Segers K², Butera Yvan ${ }^{3,4,7}$, Musoni Emile ${ }^{5}$, Uwimana Simeon ${ }^{5}$, Habanabakize Thomas ${ }^{5}$, Ruzigana Georges ${ }^{6}$, Mugenzi Pacifique ${ }^{3}$, Josse Claire ${ }^{4}$, Bours Vincent ${ }^{2 \dagger}$ and Mutesa Leon ${ }^{7 t^{*}}$

\footnotetext{
*Correspondence: Imutesa@gmail.com
}

\author{
'These are contributed equally to this work. \\ ${ }^{1}$ College of Science and Technology, University of Rwanda, Kigali, Rwanda, Africa. \\ ${ }^{2}$ Laboratory of Human Genetics, GIGA Research Institute, University of Liege, and CHU Liège, Belgium, Europe. \\ ${ }^{3}$ Department of Oncology, Radiotherapy Center, Rwanda Military Hospital, Kanombe, Kigali, Rwanda, Africa. \\ ${ }^{4}$ Department of Medical Oncology, GIGA Research Institute, University Hospital (CHU Liège), B35, -2, Liège, Belgium, Europe. \\ ${ }^{5}$ Departement of Pathology, Kigali University Teaching Hospital, Kigali, Rwanda, Africa. \\ ${ }^{6}$ Departement of Pathology, Butare University Teaching Hospital, Butare, Rwanda, Africa. \\ ${ }^{7}$ Center for Human Genetics, College of Medicine and Health Sciences, University of Rwanda, Kigali, Rwanda, Africa.
}

\begin{abstract}
Primary breast sarcoma (PBS) is a very rare disease with an annual incidence estimated to 45 cases per million. It rises from breast connective tissue and constitutes highly recurrent tumors with poor prognosis. The management of the primary breast sarcoma relies on the tumor size, histology, and requires a multidisciplinary approach. In sub-Saharan Africa PBS was very rarely reported. We are reporting here on two cases. The two cases observed in our settings were young women who presented with high-grade sarcoma showing an aggressive form, a very fast recurrence and worse prognosis within few months following the diagnosis.
\end{abstract}

Keywords: Primary breast sarcoma, young female, Rwanda

\section{Introduction}

The primary sarcoma of the breast (PBS) is a heterogeneous and a rare form of malignancy with less than $1 \%$ of all primary breast malignancies and less than $5 \%$ of all sarcomas [1-3]. Few available publications on sarcoma of the breast are limited to retrospective review of cases and clinical case reports and thus, the incidence and prevalence of PBS are not known. The majority of reported cases were in post-menopausal women with a mean age of 45-50 years old with a range of $17-89$ years old [3-5].

PBS originates in mesenchymal tissue of the breast and it is characterized by a fast growth, a poor overall prognosis and a recurrence within 6 months to 2 years after the first resection [6]. The histological subtypes include malignant fibrous histiocytoma, angiosarcoma, fibrosacoma, liposarcoma, leiomyosarcoma, spindle cell sarcoma, osteosarcoma and undifferentiated pleomorphic sarcoma $[7,8]$. Unfortunately, the management of PBS is not well defined. However, local or wide excision or total mastectomy is the first line of treatment $[9,10]$. The extend of excision depends upon the size and grade of the tumor and tumor histology [11]. After resection, late local recurrence, distant metastasis to the lungs and liver as well as to the bones were well documented $[1,2,12]$. In the breast, the sarcoma spreads via hematogenous route. Lymphadenopathy in PBS is uncommon and therefore less informative.

The use of chemotherapy and radiotherapy as adjuvant therapy of PBS is still controversial and is recommended in high grade tumors with more than $5 \mathrm{~cm}$ and in case of suspicion of tumor recurrence $[11,13,14]$.

In Sub- Saharan Africa, report on PBS was quite absent. One case was previously reported in Kenya [15].

We are reporting here two cases of sarcoma of the breast observed in young Rwandan breast cancer women. The two patients were enrolled into another study investigating germline 
Leon et al., Breast Cancer Reports 2019,

mutations in young women with breast cancer in Rwanda (Unpublished data).

\section{Description of Cases \\ Case 1}

The patient was a 34 years old female with a progressively increasing in size breast lump over three years. She did not have any known family history of cancer. Physical examination showed a firm, painless right breast mass of about $2 \times 2 \mathrm{~cm}$ that was mobile in the right upper outer quadrant. There was no skin change, no nipple retraction and no axillary adenopathy. The remainder of systemic physical examination was unremarkable. The patient underwent local excision of the mass. Intra-operatively, $6 \times 7 \mathrm{~cm}$ right cystic breast lump was found in lower medial quadrant and macroscopic examination showed fungating, grey, dark fragments of tissues with focal zones and no necrosis on cut section. The microscopic H\&E stained sections showed a malignant tumor with sarcomatoid features including frequent mitotic figures (Figure 1). Histopathological features were consistent with sarcoma / sarcomatoid high grade tumor, grade II, differentiation (2), mitotic (1) i.e $<10 / 10$ High Power Field (HPF), necrosis $<50 \%$ : margins could not be assessed since it was a local excisional biopsy (incisional). However, the mastectomy was recommended to determine if the tumor was really a sarcoma or a metaplastic tumor. The computed tomography (CT) scan of the chest was normal and no metastasis was seen. The immunohistology test showed that the tumor was negative for estrogen, progesterone and human growth factor 2 receptors. After one month, the patient was complaining about some fluids in the breast. The

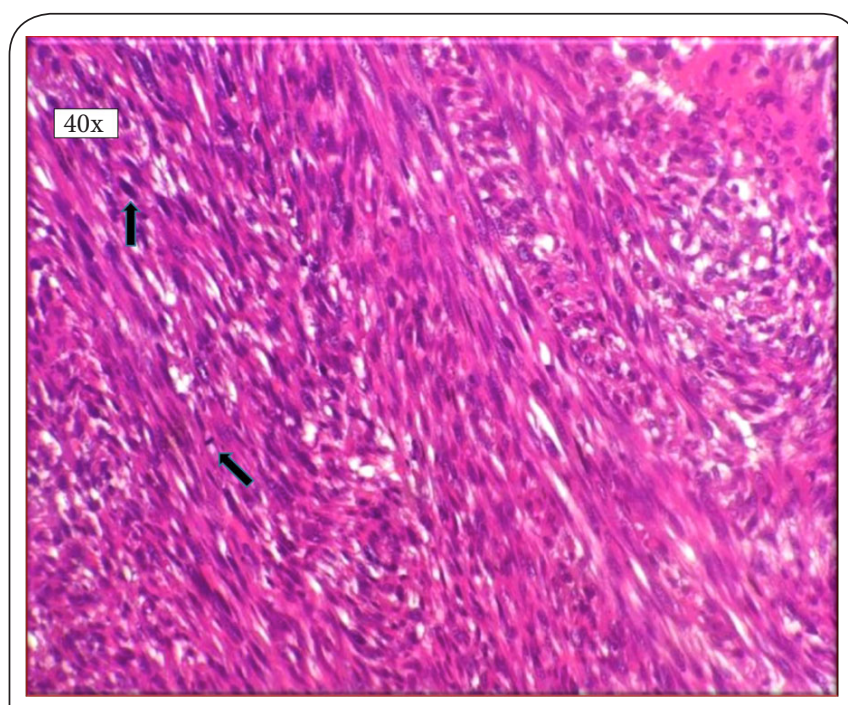

Figure 1. Photomicrograph of right breast sarcoma high grade. H\&E (40x HPF) stained sections showing haphazardly arranged spindle tumor cell with variable size somewhat disposed in fascicles, the cells have spindle to oval nuclei, inconspicuous nucleoli and moderate eosinophilic cytoplasm. Mitotic figures are frequent with a count of 5/10 HPF (black arrows). fluid was collected and the incision was healing well without infection or inflammation. The complete excision of the tumor confirmed a sarcoma of the breast. Two years later, she came back to hospital, complaining of diffuse pain, anorexia, and generalized body weakness, suggested the progression of the disease. Physical examination showed a mass of about $2.5 \mathrm{~cm}$ in diameter and the $\mathrm{CT}$ scan revealed multiple metastatic tumors in the lung, groin, liver, gluteal and bones. She underwent 9 cycles of doxorubicin. After completion of the treatment the CT scan showed new progression of the disease. The patient was not fit for palliative chemotherapy and was advised to come back with a family member for further discussion but never returned. She was lost to follow-up for a certain time period, and died. The tumor DNA was highly damaged and with poor quality and did not allow a sequencing study for determination of mutations associated with this rare form of breast cancer.

\section{Case 2}

The proband was a young woman of 17 years of age who presented to the hospital with a lump in the left breast, associated with evolutive pain, for 2 months. Her sister (46 years old) had been also diagnosed with triple negative breast cancer two years before. The physical examination showed a $2.5 \times 3 \mathrm{~cm}$ firm, mobile, painless left upper outer quadrant mass without nipple discharge and no skin change. Local excision was performed and microscopic examination concluded to a highgrade sarcoma tumor of $5 \times 6 \mathrm{~cm}$ with abundant eosinophilic cytoplasm and frequent mitotic activity with atypical forms (Figure 2). The immunohistology exam showed a triple negative tumor. The patient underwent adjuvant chemotherapy. Two months later, physical examination revealed a $5 \times 4 \mathrm{~cm}$

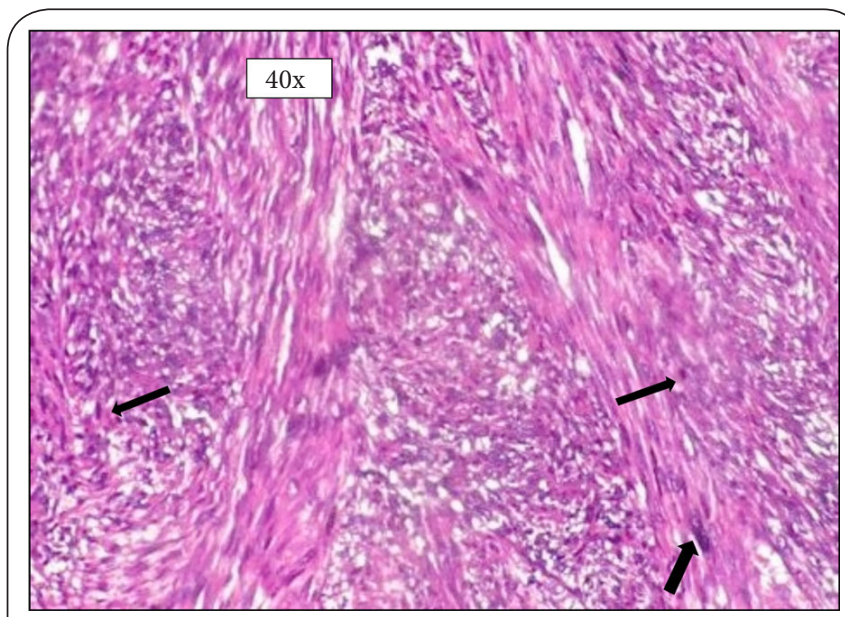

Figure 2. Photomicrograph of left breast sarcoma high grade. H\&E (40xHPF) stained sections showing a spindle cell neoplasm disposed in fascicles of spindly cells with variable size, some of which have the bizarre cigar to oval shaped type nuclei (big arrow). The cytoplasm is abundant eosinophilic. The mitotic activity was frequent with atypical forms. 
mass with small infra-clavicular lymph node metastasis. The CT scan of the chest and abdomen was normal. The wide excision was performed and the wound healed well without any seroma. The patient was tested for genetic predisposition, but the results from the next generation sequencing (NGS) of targeted amplicons (exons and flanking intronic regions) from a panel of 26 genes such as $B R C A 1, B R C A 2, C H E K 2, B A R D 1, B R I P 1$, RAD51C, RAD51D, TP53, MRE11A, RAD50, NBN, FAM175A, ATM, PALB2, STK11, MEN1, PTEN, CDH1, MUTYH, BLM, XRCC2, MLH1, MSH6, PMS2, MSH2 and the $3^{\prime} U T R$ of EPCAM, did not show any pathogenic mutation in BRCA1/2, TP53 genes or in any other gene of the panel. Five months later, after completion of chemotherapy, the patient was re-admitted to the hospital and she presented with functional impotence, sensory and motor deficit of the left upper limb. The neurological exam concluded about the sensory and motor monoparesia of the left upper limb. The CT scan revealed multiple metastatic tumors in lungs and liver. She underwent basic palliative care and died one month later.

\section{Discussion}

Primary breast sarcoma is a rare and poorly understood condition. The rarity of the disease leads to the lack of consensus on optimal treatment. The risks associated to the primary sarcoma of the breast are not known. Some suggestions include external radiation of the breast or the chest wall, pre-existing fibroadenoma and hereditary Li-Fraumeni syndrome or neurofibromatosis [16].

Large studies showed that PBS might affect women of all ages from teenagers to elder. The mean age at diagnosis was 39-52 years, which is younger age than the common epithelial breast cancer $[3,5,17,18]$. PBS are often large tumors with a median size of $4.8-5.6 \mathrm{~cm}$ at diagnosis, ranging from 0.8 to 40 $\mathrm{cm}$. Local lymph nodes metastasis was shown to be uncommon $[\mathbf{7 , 1 7 , 1 8 ]}$. However, few studies showed the presence of lymphadenopathies in $7 \%$ to $10 \%$ of cases in their series $[4,17]$. The recurrence was very common in PBS with the median time of 8.4 months ranging from 1.3 to 85.3 months [17].

The two cases observed in our settings were young women who presented with high-grade sarcoma. For the second case, the tumor recurrence was very fast and more aggressive with a very rapid spread to infra- clavicular lymph nodes and distant organs. Our results from NGS analysis of 26 breast cancer susceptibility genes including TP 53 did not show any pathogenic germline mutation. Considering the youngest age of the patients, further test investigating other possible genomic alteration that could be the associated to the disease are needed.

The first line of management of PBS is a local/ wide excision or complete mastectomy. The role of an adjuvant chemotherapy in PBS treatment is not clear. Most previous studies showed a limited response rate and authors did not draw any concensus $[3,17,18]$. However, Zelek et al. [8] showed an improvement of disease free survival and recommended the use of adjuvant chemotherapy especially in large tumors, greater than $5 \mathrm{~cm}$.

Our cases showed a very quick recurrence with a lack of response to both surgery and adjuvant chemotherapy, therefore a poor prognosis and a death within 1-2 years after diagnostic. These observations are in concordance with other studies reporting on PBS patient's prognosis $[1,7]$.

Al-Bena et al. [19] recommended the management of PBS like other soft tissue sarcoma with a multidisciplinary approach including experienced sarcoma surgeons, pathologists, radiotherapists and medical oncologists.

\section{Conclusion}

The two cases observed in our clinical settings were young women who presented with high-grade sarcoma showing an aggressive form, a very fast recurrence and worse prognosis within few months following the diagnostic. In Sub-Saharan Africa, epithelial breast cancers are characterized by different clinical and pathologic features as compared to western countries. In these two PSB cases we did not observe any difference in case characteristics compared to other reports. However, further investigations on PBS in Africa are needed considering the aggressiveness of this form of breast cancer.

\section{Competing interests}

The authors declare that they have no competing interests.

\section{Authors' contributions}

\begin{tabular}{|l|c|c|c|c|c|c|c|c|c|c|c|}
\hline $\begin{array}{l}\text { Authors' } \\
\text { contributions }\end{array}$ & UJ & SK & BY & ME & US & HT & RG & MP & JC & BV & ML \\
\hline $\begin{array}{l}\text { Research concept } \\
\text { and design }\end{array}$ & $\checkmark$ & $\checkmark$ & -- & -- & -- & -- & -- & -- & $\checkmark$ & $\checkmark$ & $\checkmark$ \\
\hline $\begin{array}{l}\text { Collection and/or } \\
\text { assembly of data }\end{array}$ & $\checkmark$ & -- & -- & -- & -- & -- & -- & -- & -- & $\checkmark$ & $\checkmark$ \\
\hline $\begin{array}{l}\text { Data analysis and } \\
\text { interpretation }\end{array}$ & $\checkmark$ & $\checkmark$ & $\checkmark$ & $\checkmark$ & $\checkmark$ & $\checkmark$ & $\checkmark$ & $\checkmark$ & $\checkmark$ & $\checkmark$ & $\checkmark$ \\
\hline $\begin{array}{l}\text { Writing the } \\
\text { article }\end{array}$ & $\checkmark$ & $\checkmark$ & -- & -- & -- & -- & -- & -- & $\checkmark$ & $\checkmark$ & $\checkmark$ \\
\hline $\begin{array}{l}\text { Critical revision of } \\
\text { the article }\end{array}$ & $\checkmark$ & $\checkmark$ & $\checkmark$ & $\checkmark$ & $\checkmark$ & $\checkmark$ & $\checkmark$ & $\checkmark$ & $\checkmark$ & $\checkmark$ & $\checkmark$ \\
\hline $\begin{array}{l}\text { Final approval of } \\
\text { article }\end{array}$ & $\checkmark$ & $\checkmark$ & $\checkmark$ & $\checkmark$ & $\checkmark$ & $\checkmark$ & $\checkmark$ & $\checkmark$ & $\checkmark$ & $\checkmark$ & $\checkmark$ \\
\hline
\end{tabular}

\section{Acknowledgement}

We thank the personnel of the anatomy pathology laboratory of Kigali Teaching Hospital for their assistance.

\section{Publication history}

Editor: Wei-Hsiung Yang, Mercer University School of Medicine, USA.

Received: 09-Oct-2019 Final Revised: 12-Nov-2019

Accepted: 15-Nov-2019 Published: 04-Dec-2019

\section{References}

1. Terrier P, Terrier-Lacombe MJ, Mouriesse H, Friedman S, Spielmann M and Contesso G. Primary breast sarcoma: a review of 33 cases with immunohistochemistry and prognostic factors. Breast Cancer Res Treat. 1989; 13:39-48. | Article | PubMed

2. Pollard SG, Marks PV, Temple LN and Thompson HH. Breast sarcoma. A clinicopathologic review of 25 cases. Cancer. 1990; 66:941-4. | Article | 
Leon et al., Breast Cancer Reports 2019,

http://www.hoajonline.com/journals/pdf/2057-1631-6-2.pdf

doi: $10.7243 / 2057-1631-6-2$

PubMed

3. Adem C, Reynolds C, Ingle JN and Nascimento AG. Primary breast sarcoma: clinicopathologic series from the Mayo Clinic and review of the literature. Br J Cancer. 2004; 91:237-41. | Article | PubMed Abstract I PubMed FullText

4. Blanchard DK, Reynolds CA, Grant CS and Donohue JH. Primary nonphylloides breast sarcomas. Am J Surg. 2003; 186:359-61. | Article | PubMed

5. Pandey M, Mathew A, Abraham EK and Rajan B. Primary sarcoma of the breast. J Surg Oncol. 2004; 87:121-5. | Article | PubMed

6. Agrawal S, Rao S and Gupta OD. Breast cancer sarcoma: A rarity. Clin cancer Investig J. 2014; 3:338-340.

7. McGowan TS, Cummings BJ, O'Sullivan B, Catton CN, Miller N and Panzarella T. An analysis of 78 breast sarcoma patients without distant metastases at presentation. Int J Radiat Oncol Biol Phys. 2000; 46:38390. | Article | PubMed

8. Zelek L, Llombart-Cussac A, Terrier P, Pivot X, Guinebretiere JM, Le Pechoux C, Tursz T, Rochard F, Spielmann M and Le Cesne A. Prognostic factors in primary breast sarcomas: a series of patients with long-term follow-up. J Clin Oncol. 2003; 21:2583-8. | Article | PubMed

9. Barrow BJ, Janjan NA, Gutman H, Benjamin RS, Allen P, Romsdahl MM, Ross $\mathrm{MI}$ and Pollock RE. Role of radiotherapy in sarcoma of the breast--a retrospective review of the M.D. Anderson experience. Radiother Oncol. 1999; 52:173-8. | Article I PubMed

10. Haberthur F, Almendral AC, Feichter G and Torhorst JK. [Sarcoma of the breast]. Helv Chir Acta. 1992; 59:221-3. I PubMed

11. Yin M, Mackley HB, Drabick JJ and Harvey HA. Primary female breast sarcoma: clinicopathological features, treatment and prognosis. Sci Rep. 2016; 6:31497. | Article | PubMed Abstract | PubMed FullText

12. Rane SU, Batra C and Saikia UN. Primary leiomyosarcoma of breast in an adolescent girl: a case report and review of the literature. Case Rep Pathol. 2012; 2012:491984. | Article | PubMed Abstract | PubMed FullText

13. Pencavel T, Allan CP, Thomas JM and Hayes AJ. Treatment for breast sarcoma: a large, single-centre series. Eur J Surg Oncol. 2011; 37:703-8. | Article | PubMed

14. Nizri E, Merimsky $O$ and Lahat G. Optimal management of sarcomas of the breast: an update. Expert Rev Anticancer Ther. 2014; 14:705-10. Article I PubMed

15. Hassan S and Adari G. Primary breast sarcoma: case report. East Afr Med J. 2004; 81:375-7. | Article | PubMed

16. Bousquet G, Confavreux C, Magne N, de Lara CT, Poortmans P, Senkus E, de Lafontan B, Bolla M, Largillier R, Lagneau E, Kadish S, Lemanski C, Ozsahin $\mathrm{M}$ and Belkacemi Y. Outcome and prognostic factors in breast sarcoma: a multicenter study from the rare cancer network. Radiother Oncol. 2007; 85:355-61. | Article | PubMed

17. Confavreux C, Lurkin A, Mitton N, Blondet R, Saba C, Ranchere D, Sunyach MP, Thiesse P, Biron P, Blay JY and Ray-Coquard I. Sarcomas and malignant phyllodes tumours of the breast--a retrospective study. Eur J Cancer. 2006; 42:2715-21. | Article | PubMed

18. Fields RC, Aft RL, Gillanders WE, Eberlein TJ and Margenthaler JA. Treatment and outcomes of patients with primary breast sarcoma. Am J Surg. 2008; 196:559-61. | Article | PubMed

19. Al-Benna S, Poggemann K, Steinau HU and Steinstraesser L. Diagnosis and management of primary breast sarcoma. Breast Cancer Res Treat. 2010; 122:619-26. | Article | PubMed

\section{Citation:}

Uyisenga JP, Segers K, Yvan B, Emile M, Simeon U, Thomas H, Georges R, Pacifique M, Claire J, Vincent $B$ and Leon M. Primary sarcoma of the breast in the young Rwandan females. Breast Cancer Rep. 2019; 6:2. http://dx.doi.org/10.7243/2057-1631-6-2 